\title{
Sustaining HIV Prevention, Care and Treatment Programmes for the Youths in Chipata Districts through Youth Leadership
}

\author{
Njovu CA*
}

\author{
Chisomo Community Programme, Zambia
}

*Correspondingauthor: NjovuCA,Chisomo Community Programme,Zambia,E-mail:chisomoprogramme@ gmail.com

Citation: Njovu CA (2017) Sustaining Hiv Prevention, Care and Treatment Programmes for the Youths in Chipata Districts through Youth Leadership. J Aids Hiv Infet 3(2): 202. doi: 10.15744/2454-499X.3.202

Received Date: October 17, 2016 Accepted Date: December 27, 2017 Published Date: December 29, 2017

\section{Introduction}

Comprehensive HIV prevention information, access and utilization of Sexual and Reproductive Health(SRH) services, is low among the migrants mobile and displaced populations of our catchment area namely Katete, Chadiza and Chipata in district in the eastern province of Zambia. This is one of the provinces with a highest number of, migrants; sex workers truck drivers and cross border traders due to the economical Nacala corridors that bring the three countries namely Zambia, Malawi and Mozambique, also the traditional ceremonies that bring the three countries together each year has seen high numbers of people migrate between the three countries this has led to high numbers of STIs, HIV and unsafe abortions. Alcohol and substance abuse, peer pressure among this population.

Although the relationships between HIV and SRH are well recognized, migrants, mobile and displaced populations still face difficulties in accessing SRH services. Difficulties in accessing SRH services tailored to meet the needs of this population often results in marginalization of this group, who frequently end up self-administering medication which is dangerous as they may take wrong drugs for a particular illness.

Poor accessibility to SRH services has resulted into as many as 60 per cent of the immigrants, mobile and displaced populations having unintended pregnancies as well as an increase in STIs which has subsequently resulted into a decline in health and an increase in the likelihood of HIV transmission and re-infection for these immigrants, mobile and displaced populations. Studies have indicated that access to SRH services is even poorer among the 'hard to reach' groups which include immigrants, mobile and displaced populations living with HIV and female sex workers (FSWs) among others. The SRH needs of immigrants, mobile and displaced populations living with HIV are largely unmet, resulting in widespread misconceptions and misinformation regarding fundamental aspects of prevention and reproductive life.

The high poverty and employment levels have affected the immigrants, mobile and displaced populations' accessibility to health services in Zambia. According to the 2007 Zambia Demographic Health Survey about 44\% of the immigrants, mobile and displaced populations are unemployed. Because of poverty, some of the immigrants, mobile and displaced populations have been forced into health risky behaviors such as sex work especially female immigrants, mobile and displaced populations with little or no information on SRHR.

Immigrants and mobile populations are also generally despised, marginalized and discriminated against in the communities and by themselves may be cause they do not have proper documents for them access health services when they go to seek for (SRHR) services such as family planning, while sexual activity is happening and HIV prevalence among this group is reported to be increasing especially among females. In order to increase access to SRH services IOM Zambia funded Chisomo to design and implement an intervention to increase Immigrants and mobile population access to SRH services with a primary focus on HIV testing to know their HIV status in order to access prevention for those who are negative, care and support services for those who are positive and increase and encourage disclosure among the Immigrants and mobile population.

The programme support aimed at improving access to SRH services among the Immigrants and mobile population in Chipata Mwami border, Katete and Chadiza districts Chanida border to Mozambique. This innovative approach was called the Immigrants and mobile population leadership approach.

The project was innovative as it aimed to improve access to SRH services through Integrating friendly SRH services for Immigrants and mobile population into the health system at district, community and border level. Innovations refer to new ideas, programmes, 
projects and health technologies which are perceived as fresh by the adopting individual, community or unit.

The approach is to specifically focus at meeting the SRH needs of Immigrants and mobile populations which include female sex workers.

\section{Methods}

\section{Data collection}

Data collection was done using in-depth interviews, FGDs, observations using gender transformative approach. Data collectors which included the Immigrants and mobile population were used in conducting the interviews and FGDs. Key themes covered in the guides were type of project activities, type of information and services provided in the community for the Immigrants and mobile population, who provided the information and services, how often are these issues provided and where there are provided from. Other key themes were the quality, relevance, utilization and limitations of the information and services as well as recommendations for improving the project implementation process.

\section{In-depth interviews}

Following an initial data collection, most other data collection activities took place during a five-day visit to the border areas in the three districts the department of health, immigration the district education board, trading areas and other CBOs, and health centers in the districts. In-depth interviews were conducted with Immigrants and mobile population including female sex workers, key stakeholders in the community and staff members at the implementing CBO. Two youths participated in-depth interviews: one, a community leader in the community and the other a project beneficiary. In-depth interviews were also conducted with Chisomo staff members. On average, each interview lasted between 45 minutes and an hour [1].

\section{Focus group discussion}

Ten FGDs were also conducted five for male youths and five for female youths. Two brought together youth participants who were primarily beneficiaries of Chisomo activities, and another with youth participants who were not beneficiaries of the implementing CBO.

\section{Observations}

We also visited the youth clubs in order to understand how the information flows in clubs three community youth clubs were visited. The other reason for undertaking the observations was to understand how the services are provided in the youth clubs and also conduct informal discussions with some of the youths that were living in these areas to assess the acceptability and adoption of the SRH services through youth leadership [2].

\section{Discussion}

Implemented between January 2014 and March 2015, 5 school-based youth clubs comprised of 10 members our desire is to have equal number for female and male but in some schools it is more girls than boys and 5 community based clubs comprised of 10 people per club were established in the five wards. Information and weekly activities developed with youth involvement which includes orientation meetings, Focus group discussions, one on one and feedback meetings. Youths were required to present their weekly tasks which include counselling scouting others to health service providers, making referrals and coming up a with program for the week taking minutes during meetings to club members with each member given a chance to lead a session (Figure 1 and 2).

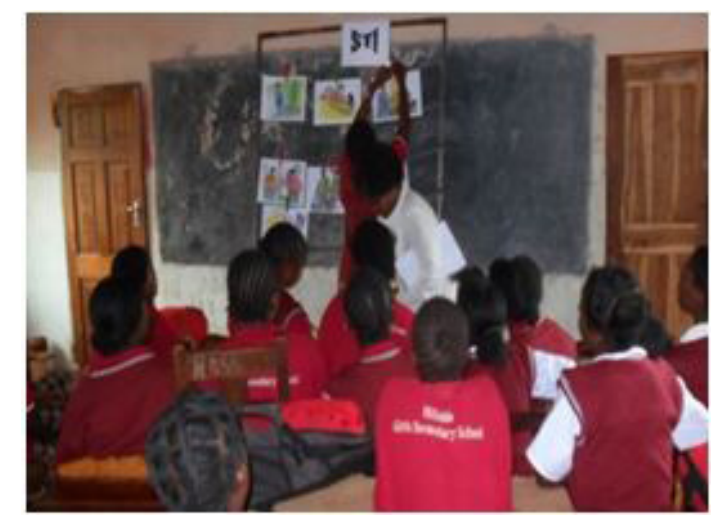

Figure 1: In schools

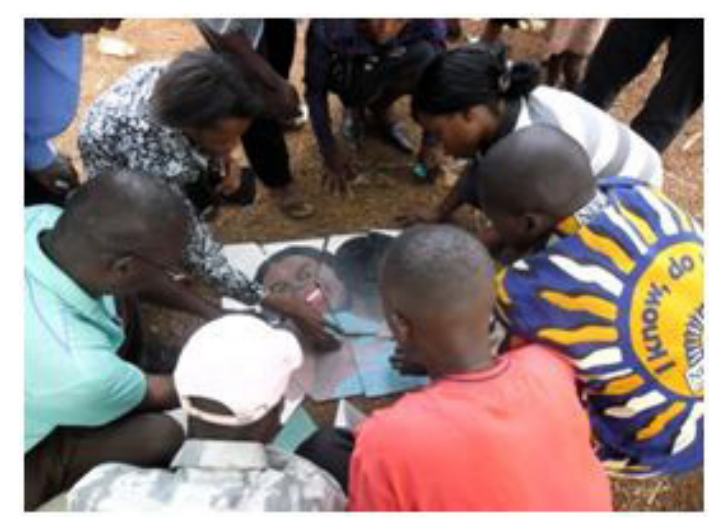

Figure 2: In the community

Before then all five schools had these clubs but were not functional but with this intervention now they are functional and reaching out to 300 youths with information on SRHR per month meaning that more youth access SRH information through these clubs, 
this is so because Chisomo oriented the guidance teachers in SRH and they have taken up leadership in making sure that these clubs meet when they are to meet. Averages of 10 youths in these clubs have testified of being assistive and this is due to increased dialog, knowledge and access to SRH information [3].

A mapping using the Gender Transformative Approach (GTA) showed that youths involved in club activities demonstrated increased understanding of transmission modes of HIV as well as the risk of HIV infection due to having many sexual partners. They also demonstrated knowledge of risk of infection within such multiple relationships. Access to HTC increased through referrals they organize. There is reduction in the number of sexual partners among older youths others had three but have reduced to one partner. Communication with parents improved due to community meetings on SRHR for the youths in the community, while teenage pregnancies and school drop outs among girls decreased within the period of implementation in the targeted schools e.g. one school before the interventions had 54 pregnancies in a year but after implementation reduced to 26 in 2015. Youths acquired other skills such as presentation and leadership skills (Table 1).

This has reviewed the factors that shaped integration Process of the youth participation into the health system at community level in the district is working. Factors are that facilitated the integration Process included the perceived relative advantage of the project over other existing SRH strategies. The inclusion of the youth at all levels of programming to implementation consisting of different stakeholders made the project to be perceived as more advantageous than other existing SRH strategies. The youths facilitated integration of the project into the service delivery health systems function in the community. This integration was possible because the members of youth groups were in position thereby easily advocating for increased attention towards the needs of the youths within their respective organizations and institutions which included health facilities and the schools. Key positive outcomes of this advocacy included some health workers developing a positive attitude towards the youths and improved referral system for SRH services for the youths. Good communication processes helped overcome tension among relevant stakeholders In addition, the use of structures at community level such as Youth clubs to deliver SRH services to youths facilitated the compatibility of the project with the health system functions such as the population or community and health service delivery. This was possible because of the use of youths was in line with youths expectations of what friendly SRH friendly services should be like; since offering services at such points reduced stigmatization and distances to SRH service points. The use of the school youth clubs and youth leadership in the project in general facilitated the integration process by enhancing the youth's confidence into the services provided by the project. Further, involvement of the community structures such as community youth clubs and also peer educators facilitated the community's sense of programme ownership. Whereas community participation and involvement of stakeholders from the government and NGO sector through the CBO facilitated the integration process by triggering the perceived legitimacy, credibility and relevance of project among the youths. These attributes are similar among adolescents who showed for that selfconfidence by local stakeholders in SRH services as well as the perceived legitimacy and relevance of the SRH services by the adolescents positively facilitated the uptake of the services.

\section{Results}

\begin{tabular}{|c|c|c|c|c|c|}
\hline Year & Before & INTERVENTIONS & & AFTER & \\
\hline & $\begin{array}{l}\text { Number of } \\
\text { pregnancies }\end{array}$ & & & $\begin{array}{l}\text { Number of } \\
\text { pregnancies }\end{array}$ & Outcomes \\
\hline 2014 & 54 & $\begin{array}{l}\text { Orientation of teachers and } \\
\text { club leaders in SRHR }\end{array}$ & 2015 & 26 & $\begin{array}{l}\text { Increased knowl- } \\
\text { edge on SRH and } \\
\text { reduced number of } \\
\text { girls dropping out } \\
\text { of school due to } \\
\text { pregnancies, }\end{array}$ \\
\hline 2014 & 54 & $\begin{array}{c}\text { Formation of safe clubs in } \\
\text { schools and clubs in com- } \\
\text { munities }\end{array}$ & 2015 & 26 & $\begin{array}{l}\text { Increased youth } \\
\text { participation and } \\
\text { decision making on } \\
\text { issues of SRH. }\end{array}$ \\
\hline 2014 & 54 & Youth led activities & 2015 & 26 & $\begin{array}{l}\text { Increased youth led } \\
\text { dialogues }\end{array}$ \\
\hline 2014 & 54 & $\begin{array}{c}\text { Greater youth involvement } \\
\text { at all levels }\end{array}$ & 2015 & 26 & $\begin{array}{l}\text { Reduced abortions } \\
\text { among girls and } \\
\text { reduced child mar- } \\
\text { riages }\end{array}$ \\
\hline
\end{tabular}

Table 1: Number of pregnancies before interventions and after outcomes

\section{Lessons Learned}

Active participation of youths in SRH and HIV prevention activities has the potential to build their ability to demand and access SRH services. Interventions for youths must focus on building skills and making them "do it for themselves." Building a supportive environment is important. The GTA and the youth involvement approach can be used beyond SRH issues as it has proved to be empowering. 


\section{Next Steps and Recommendations}

There is a need to scale up the intervention and have further evaluations to validate its impact for decision making in terms of replication. The project has been extended within the districts and has raised demand from other areas in district because of its impact.

\section{References}

1. A mapping report of the gender transformative approach conducted in Chipata district by Chisomo community programme.

2. School data and registers on the school drop outs due to pregnancies.

3. Data in youth clubs and in schools and in the community.

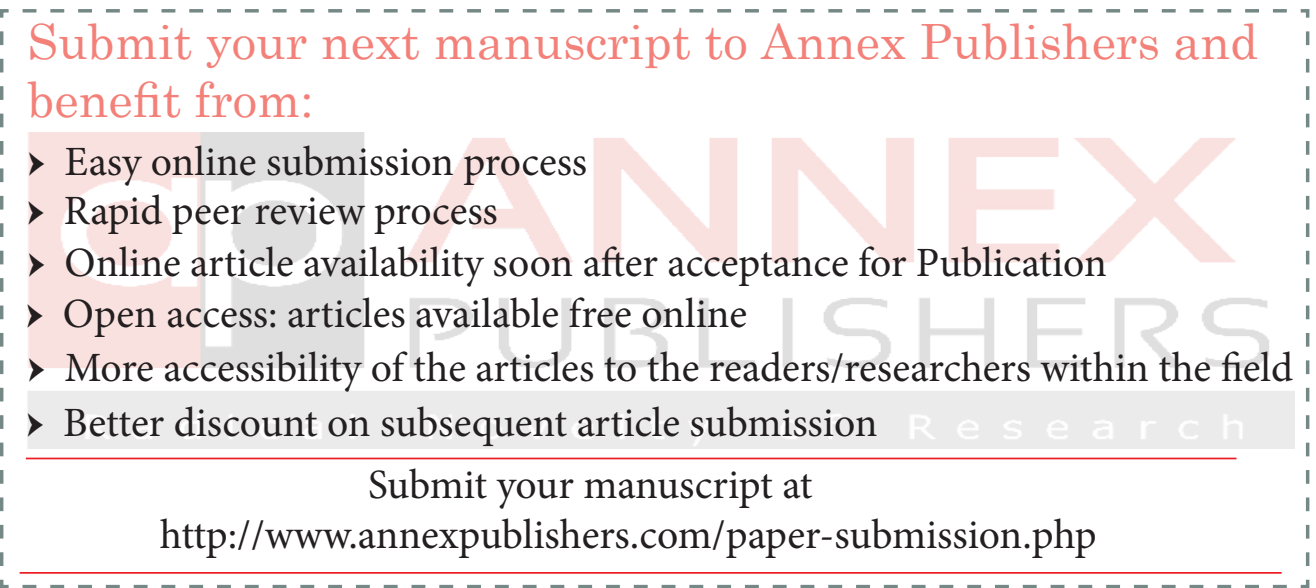

